\title{
Pacemaker Procedure
}

National Cancer Institute

\section{Source}

National Cancer Institute. Pacemaker Procedure. NCI Thesaurus. Code C99998.

A procedure involving an electronic device that delivers electrical stimulation to the heart to treat bradycardia. (ACC) 